\title{
Epidemiological and public health aspects of oral contraceptives and thromboembolic disease
}

\author{
MARTIN P. VESSEY \\ From the Department of the Regius Professor of Medicine, Radcliffe Infirmary, Oxford
}

SYNOPSIS The evidence relating oestrogen-progestogen oral contraceptives to venous throme-
bosis, pulmonary embolism, and cerebral thrombosis is reviewed. The risks associated with the्ष
use of oral contraceptives are then discussed in relation to the risks associated with the use of
less effective methods of birth control.

The possibility that the use of oral contraceptives might increase the risk of thromboembolic disease was first raised by a case report in the Lancet in 1961 (Jordan, 1961). The patient concerned was a 40-year-old nurse who had been given Enavid for the control of endometriosis. After some weeks, the treatment had to be discontinued because of severe vomiting. Ten days later, that is, one week after the vomiting had stopped, the patient developed pulmonary embolism. Since that time many hundreds of similar case histories have been published in the medical journals or reported to national adverse drug reaction committees. The majority of these reports describe deep venous thrombosis of the lower limbs or pulmonary embolism, but others relate to cerebrovascular accidents, coronary thrombosis, mesenteric and other arterial thrombosis, and the Budd-Chiari syndrome.

All these disorders also occur in young women who do not use oral contraceptives and, in themselves, the case reports provide no valid evidence that the preparations are a cause of the diseases in question. For further progress, it is necessary to make estimates of the incidence of the diseases in women using oral contraceptives and to compare them with the incidence in women not doing so. This, of course, was appreciated at

${ }^{1}$ This paper is based in part on an article submitted for publication to the British Medical Bulletin. once, and between 1962 and 1966 a number of such comparisons were made (Searle \& $\mathrm{Co}_{\overrightarrow{\mathrm{F}}}$ Chicago Conference, 1962; United States Foog and Drug Administration 1963, 1966; Cahah 1965). Each of these comparisons, howeve lacked satisfactory control data and depended on. the voluntary notification of episodes of thrombo embolism by doctors for the calculation of morbidity or mortality rates in users of ora contraceptives. These serious inadequacies in evitably led to inconclusive results and the prob lem remained unresolved until three controlleg investigations were undertaken in the United Kingdom during 1966.

The three British studies were all of the retros spective or case-control type. In one, organized by the Royal College of General Practitioners (1967), 29 family doctors interviewed 147 marriean women aged 15-49 years who had consulted the for an episode of thromboembolic disease. Inca second, Vessey and Doll $(1968,1969)$ investigated 131 married women aged 16-40 years admittey to one or other of 19 large general hospitals during 1964-67 with thromboembolic diseas without evident predisposing cause. In the thir $\Phi_{\text {. }}$ Inman and Vessey (1968) investigated all the 498 deaths that had occurred in England, Wales, and Northern Ireland during 1966 in women aged 20-44 years in which thrombosis or embolism of the pulmonary, cerebral, or coronary vesses 
was mentioned on the death certificate. For comparative purposes, control series of women, matched to correspond with the affected patients in a number of important respects, were investigated in each of the three studies by methods similar to those that had been used for the patients with thromboembolism.

The study carried out by the Royal College of General Practitioners was concerned principally with the common condition, superficial thrombophlebitis, and it indicated that the risk of developing this disorder was increased threefold among women who were using the contraceptives. The principal results of the other two investigations are summarized in Table I. In the absence of any evident predisposing cause, the risk of hospital admission or death from deep vein thrombosis, pulmonary embolism, or cerebral thrombosis was found to be increased six to eight times by the use of the preparations. In contrast, no significant evidence was obtained that oral contraceptives are a cause of coronary thrombosis.

Retrospective studies are subject to many sources of bias and the results shown in Table I should not be accepted uncritically. In particular, they might have teen produced if doctors diagnosed thromboembolic disease more readily, or admitted patients to hospital more readily, when they obtained a history of the use of oral contraceptives than when they did not. Two pieces of evidence suggest that this type of bias is unlikely to explain the results. First, if diagnostic bias were a major factor, the association between the use of oral contraceptives and thromboembolism should be strongest in those patients with the least objective evidence of the disease. In fact, the reverse was found to be true. In the investigation of Vessey and Doll, the proportion of patients who were using oral contraceptives rose from $38 \%$ of those with an uncertain diagnosis to $68 \%$ of those in whom the diagnosis was established. Secondly, the number of admissions to hospital for venous thrombo- embolism among women using oral contraceptives increased progressively with the increase in the use of oral contraceptives in the general population, and no increase in the admission rate occurred after periods of maximum publicity concerning the thromboembolic hazards of the preparations.

At the time that the three British epidemiological investigations were being planned, a study very similar to the one carried out by Vessey and Doll was teing developed, quite independently, in the United States. The findings in this investigation have now keen reported (Sartwell, Masi, Arthes, Greene, and Smith, 1969). One hundred and seventy-five women aged 15-44 discharged alive from 43 hospitals after initial attacks of 'idiopathic' thrombophlebitis, pulmonary embolism, or cerebral thrombosis or embolism, were identified, together with 175 carefully matched controls. All subjects were interviewed to provide information concerning their use of oral contraceptives before admission to hospital. From these data, it was estimated that the risk of admission to hospital for superficial thrombophlebitis was increased by the use of oral contraceptives 3.0 times, for deep vein thrombosis or pulmonary embolism 4.4 times, and for cerebral thrombosis $7 \cdot 0$ times. Considering the small numbers of subjects involved both in the British and in the American investigations, the degree of agreement between the findings in the various studies is remarkable.

In addition to the results of these four epidemiological investigations, there is a substantial body of evidence which offers indirect support to the view that oral contraceptives are a cause of thromboembolic disease. In the case of venous thrombosis and pulmonary embolism, this additional evidence may be summarized as follows:

1 At a number of centres, physicians have reviewed their total clinical experience of venous thromboembolism over a period of time. To draw any conclusions from such reviews, it is

\begin{tabular}{|c|c|c|c|c|c|c|}
\hline \multirow[t]{3}{*}{ Disorder } & \multirow[t]{3}{*}{ Source of Data } & \multirow{2}{*}{\multicolumn{2}{|c|}{$\begin{array}{l}\text { No. of Women with a } \\
\text { Thromboembolic Disorder } \\
\text { with a History of Oral } \\
\text { Contraceptives }\end{array}$}} & \multicolumn{2}{|c|}{ No. of Women Studied } & \multirow{3}{*}{$\begin{array}{l}\text { Relative Risk } \\
\text { Users to } \\
\text { Non-users }\end{array}$} \\
\hline & & & & \multirow{2}{*}{$\begin{array}{l}\text { With } \\
\text { Thrombo- } \\
\text { embolism }\end{array}$} & \multirow[t]{2}{*}{ Control } & \\
\hline & & Used & Not Used & & & \\
\hline $\begin{array}{l}\text { Deep vein thrombosis or pulmonary } \\
\text { embolism } \\
\text { Cerebral thrombosis } \\
\text { Coronary thrombosis }\end{array}$ & $\begin{array}{l}\text { Inpatients } \\
\text { Deaths } \\
\text { Inpatients } \\
\text { Deaths } \\
\text { Inpatients } \\
\text { Deaths }\end{array}$ & $\begin{array}{rr}42 & (11 \cdot 5)^{2} \\
16 & (4 \cdot 2) \\
11 & (3 \cdot 5) \\
5 & (1 \cdot 5) \\
2 & (2 \cdot 1) \\
18 & (11 \cdot 4)\end{array}$ & $\begin{array}{r}42(72 \cdot 5) \\
10(21 \cdot 8) \\
8(15 \cdot 5) \\
5(8 \cdot 5) \\
15(14 \cdot 9) \\
66(72 \cdot 6)\end{array}$ & $\begin{array}{l}84 \\
26 \\
19 \\
10 \\
17 \\
84\end{array}$ & $\begin{array}{l}168 \\
998 \\
3 \\
3 \\
3 \\
3\end{array}$ & $\begin{array}{l}6 \cdot 3: 1 \\
8 \cdot 3: 1 \\
6 \cdot 1: 1 \\
5 \cdot 7: 1 \\
0 \cdot 9: 1 \\
1 \cdot 7: 1\end{array}$ \\
\hline
\end{tabular}

Table I. Use of oral contraceptives by women suffering from thromboembolic disorders without evident predisposing cause ${ }^{1}$

${ }^{1}$ Data from series of Vessey and Doll (1969) and Inman and Vessey (1968)

'Expected numbers in parentheses

${ }^{3} \mathrm{As}$ in corresponding control groups for women with deep vein thrombosis or pulmonary embolism 
necessary, of course, to assume a knowledge of the general use of oral contraceptives in the population at large. In one of these investigations Hobel and Mishell (1968) studied all 22 female patients aged 15-45 who had had a diagnosis of pulmonary embolism established by radioisotopic lung scanning from December 1964 to August 1967 at Harbor General Hospital, California. Of these 22 patients, three had embolization after a major operation, two after severe trauma, and three in the puerperium. The remaining 14 had pulmonary embolism (with or without venous thrombosis) in the absence of any predisposing cause. Of these, no fewer than 10 had been taking contraceptive steroids. An equally impressive clinical series has been reported from Denmark by Isager and Pedersen (1966). Only one series, that of Johnson and Rosen (1966), has been reported as having a negative result. Close scrutiny of the data shows, however, that only six patients aged 15-39 were identified who had 'idiopathic' thromboembolism and of these one had had a hysterectomy. Of the remaining five, two had been using oral contraceptives.

All these data must, of course, be interpreted with caution not only because of the absence of any control information but also because it is difficult to avoid the suspicion that negative series would have been less likely to be reported than positive ones.

2 Official mortality statistics for venous thromboembolism have been analysed for England and Wales by Vessey and Weatherall (1968) and for the United States by Markush and Seigel (1969) and Seigel and Markush (1969). In both countries there has been a trend in the national death rates in young women compatible with the increase in the use of oral contraceptives and with the estimates of the risks associated with them.

3 Oestrogens, albeit in large doses, have been implicated as a factor in the causation of puerperal thromboembolism when they are used to suppress lactation (Daniel, Campbell, and Turnbull, 1967; Jeffcoate, Miller, Roos, and Tindall, 1968).

4 Oestrogens have been shown to be a cause of thromboembolism, both arterial and venous, when they are administered to elderly men with arterial disease or cancer of the prostate (Schrogie and Solomon, 1967; Bailar, 1967).

5 A large and confused literature has accumulated relating oral contraceptives to changes in circulating levels of various coagulation factors (see Drill, 1966, and Tausk, 1968, for reviews). There is little doubt that some changes, notably increases in factors VII and X, are common, and although the significance of such changes is uncertain, they are at least consistent with the epidemiological findings.

6 Bolton, Hampton, and Mitchell (1968) have described an increase in platelet sensitivity to adenosine diphosphate as determined by the electrophoretic technique in subjects taking orato contraceptives, with a return of platelet behaviour to normal between treatment cycles. These changes in platelet behaviour are similar to those described by the same authors in patients with? occlusive vascular disease.

7 Other workers (Danforth, Maralo-Estrella흠 and Buckingham, 1964; Goodrich and Wood? 1964; Neistadt, Schwartz, and Schwartz, 1966 have demonstrated changes in vessel walls and in venous distensibility and blood flow produced by the administration of oral contraceptives in man and in animals.

Some of the evidence just described is also relevant to the occurrence of cerebral thrombosis? but in this connexion special mention must bés made of several impressive but uncontrolled clinical series of ischaemic strokes in youngwomen that have been reported in the literature $ᄋ$ Heyman, Arons, Quinn, and Camplong (1969)웅 for example, studied all female patients aged 15-39 years seen at Duke University Hospitale North Carolina, from 1958-68, in whom diagnosis of cerebral arterial occlusion withoue evident predisposing cause was made. In the intervals 1958-60, 1961-64, and 1965-68, the numbers of patients seen who were not using oral contraceptives were four, four, and five respectively. The corresponding numbers whos were using oral contraceptives were none, three $\frac{\overline{0}}{0}$ and seven respectively. Equally striking result\$ have been published by Bickerstaff and Holme 8 (1967) and by Bergeron and Wood (1969), while Illis, Kocen, McDonald, and Mondkar (1965)욕 Shafey and Scheinberg (1966), and Cole (1967 have all reported comparable findings. Onl Jennett and Cross (1967) have reported negative results. All these data must, however, be intero preted with caution, for the reasons that have been stated previously.

\section{Type of Preparation and Duration of Use}

None of the epidemiological data available at present indicate that the risk of thromboembolism is any greater early in the course of medication when it might be expected to be concentrated if the effect was an idiosyncratic reaction in specially susceptible fraction of the populatione nor that it increases with increasing duration of use.

Extensive data are required to make adequateo comparisons between the risks associated wit different oral contraceptive formulations. Inma $\$$ and Vessey (1968) and Vessey and Doll (1969) were unable to detect any such differences, but the results of the American study (Sartwell et at 1969) suggest that sequential formulations arg more hazardous than combined ones. 


\section{Genetic Factors}

A recent investigation (Jick, Slone, Westerholm, Inman, Vessey, Shapiro, Lewis, and Worcester, 1969) has provided strong evidence that the risk of venous thromboembolism in association with the use of oral contraceptives is only about onethird as great among women belonging to blood group $\mathrm{O}$ as among those belonging to the other three groups. Comparable data have yet to be obtained for cerebral thrombosis and it cannot be assumed that the same genetic factors affect the risk of this condition which affects the arteries rather than the veins.

\section{Size and Significance of the Risk}

Quantitative data that provide an indication of the absolute size of the risk (as opposed to the relative size of the risk) associated with the use of oral contraceptives have been obtained only from the British epidemiological studies and these are shown in Table II. The impact of the risk to life

\begin{tabular}{lllll}
\hline $\begin{array}{l}\text { Oral } \\
\text { Contraceptives }\end{array}$ & \multicolumn{2}{l}{ Hospital Admissions } & & Fatalities \\
\cline { 2 - 2 } & Ages 16-40 & & Ages 20-34 & Ages 35-44 \\
\hline Used & 50 & $1 \cdot 5$ & 3.9 \\
Not used & 6 & 0.2 & 0.5 \\
\hline
\end{tabular}

Table II Annual hospital admission and mortality rates for deep vein thrombosis, pulmonary embolism, and cerebral thrombosis per 100,000 previously healthy women by use of oral contraceptives

is, perhaps, better understood if it is compared with the risks from other conditions that are better known and, in particular, with the risk that is associated with pregnancy. Some of these risks are summarised in Table III, from which it all attributable causes associated with one pregnancy.

From the public health point of view, however, it must be remembered that oestrogen-progestogen oral contraceptives, especially of the combined type, offer almost complete protection against pregnancy. All other methods are substantially less effective and in assessing the significance of the thromboembolic risks of oral contraception, due consideration must be given to the dangers of unwanted pregnancy.

For comparative purposes, adequate morbidity data are not available, but in regard to mortality, approximate calculations using widely accepted failure rates for alternative methods of birth control suggest that the thromboembolic hazards in women using oral contraceptives may be approximately balanced by the risks associated with unwanted pregnancies in women using the sheath or the diaphragm. The intrauterine device, on the other hand, shows itself in a favourable light in this type of calculation because it provides more effective contraception than the occlusive methods, but its apparent advantage may be offset by the dangers of uterine perforation and sepsis which have yet to be quantified (Scott, 1968).

For the woman who, for any reason, finds oral contraception the only satisfactory method of birth control, the thromboembolic hazards should, therefore, prove acceptable. For the woman who is prepared to attend assiduously to an effective occlusive method, however, the decision may be less simple as it has been shown that among the highly motivated, failure rates well below those that are generally quoted may be obtained by such means (Sagi, Potter, and Westoff, 1962). It should also be remembered that the use of oral contraceptives is known to entail risks other than the thromboembolic ones (Doll and Vessey, 1970) and that our knowledge of the long-term effects of medication is still very incomplete.

\section{Future Work}

Each of the four controlled epidemiological studies has provided estimates of the risk of thromboembolism only for women who were previously in good health. It is, however, of considerable importance to know how the risk is affected in patients who have other predisposing conditions and, in particular, in those who have recently undergone surgery. This aspect of the problem may be satisfactorily evaluated by further case-control investigations.

There is also a need to confirm the results of the retrospective investigations by prospective studies of which at least three are now in progress (see Doll and Vessey, 1970). Such studies, however, will be extremely difficult to carry out and 
will be subject to many of the sources of bias which could have affected the results of the casecontrol investigations. It is, in fact, quite possible that they will add little to our existing knowledge of the problem.

\section{References}

Bailar, J. C. (1967). Thromboembolism and ozstrogen therapy. Lancet, 2, 560.

Bergeron, R. T., and Wood, E. H. (1969). Oral contraceptives and cerebrovascular complications. Radiology, 92, 231-238.

Bickerstaff, E. R., and Holmes, J. M. (1967). Cerebral arterial insufficiency and oral contraceptives. Brit. med. J., 1, 726729.

Bolton, C. H., Hampton, J. R., and Mitchell, J. R. A. (1968). Effect of oral contraceptive agents on platelets and plasma phospholipids. Lancet, 1, 1336-1341.

Cahal, D. A. (1965). Safety of oral contraceptives. Brit. med. J., $2,1180$.

Cole, M. (1967). Strokes in young women using oral contraceptives. Arch. intern. Med., 120, 551-555.

Danforth, M., Maralo-Estrella, P., and Buckingham, J. C. (1964) The effect of pregnancy and of Enovid on the rabbit vasculature. Amer. J. Obstet. Gynec., 88, 952-962.

Daniel, D. G., Campbell, H., and Turnbull, A. C. (1967) Puerperal thromboembolism and suppression of lactation. Lancet, 2, 287-289.

Doll, R., and Vessey, M. P. (1970). Evaluation of rare adverse effects of systemic contraceptives. Brit. med. Bull., 26, 33-38.

Drill, V. A. (966). Oral Contraceptives. McGraw-Hill, New York

Goodrich, S. M., and Wood, J. E. (1964). Peripheral venous distensibility and velocity of venous blood flow durıng pregnancy or during oral contraceptive therapy. Amer. J. Obstet. Gynec., 90, 740-744.

Heyman, A., Arons, M., Quinn, M., and Camplong, L. (1969) The role of oral contraceptive agents in cerebral arterial occlusion. Neurology (Minneap.), 19, 519-524.

Hobel, C. J., and Mishell, D. R., Jr. (1968). Pulmonary embolism and oral steroidal contraceptives. Amer. J. Obstet. Gynec., 101, 994-996.

Illis, L., Kocen, R. S., McDonald, W. I., and Mondkar, V. P. (1965). Oral contraceptives and cerebral arterial occlusion. Brit. med. J., 2, 1164-1166.

Inman, W. H. W., and Vessey, M. P. (1968). Investigation of deaths from pulmonary, coronary, and cerebral thrombosis and embolism in women of child-bearing age. Brit. med. $J ., 2,193-199$.

Isager, H., and Pedersen, K. (1966). Thromboembolic disorders and gestagen-estrogen treatment. A retrospective review of thromboembolic diseases in young women hospitalised in the Glostrup and Gentofte Hospitals in the period from 1.1.65 to 31.3.66 (Danish). Ugeskr. laeg., 128, 871-874.

Jeffcoate, T. N. A., Miller, J., Roos, R. F., and Tindall, V. R. (1968). Puerperal thromboembolism in relation to the inhibition of lactation by oestrogen therapy. Brit. med. J., 4, 19-25.

Jennett, W. B., and Cross, J. N. (1967). The influence of pregnancy and oral contraception on the incidence of strokes in women of child-bearing age. Lancet, 1, 1019-1023.

Jick, H., Slone, D., Westerholm, B., Inman, W. H. W., Vessey, M. P., Shapiro, S., Lewis, G. P., and Worcester, J. (1969). Venous thromboembolic disease and ABO blood type Lancet, 1, 539-542.

Johnson, R., and Rosen, M. G. (1966). Oral contraceptive medications and thrombophlebitis. N.Y. St. J. Med., 66, 2663-2666.

Jordan, W. M. (1961). Pulmonary embolism. Lancet, 2, 1146-1147.

Markush, R. E., and Seigel, D. G. (1969). Oral contraceptives and mortality trends from thromboembolism in the United States. Amer. J. Publ. Hlth., 59, 418-434.

Neistadt, A. Schwartz, R. W., and Schwartz, S. I. (1966). Norethynodrel with mestranol and venous blood flow. J. Amer. med. Ass., 198, 784-785.
Royal College of General Practitioners (1967). Oral contraception and thromboembolic disease. J. roy. Coll. gen. Practnrs, 13, 267-279.

Sagi, P. C., Potter, R. G., and Westoff, C. F. (1962). Contraceptivd effectiveness as a function of desired family size. Population Studies, 15, 291-296.

Sartwell, P. E., Masi, A. T., Arthes, F. G., Greene, G. R., and: Smith, H. E. (1969). Thromboembolism and oral contra ceptives: an epidemiological case control study. Amer. Jঙ++ Epidem., 90, 365-380.

Schrogie, J. J., and Solomon, H. M. (1967). Estrogenic hormone and blood coagulation. J. chron. Dis., 20, 675-678.

Scott, R. B. (1968). A survey of deaths and critical illnesses in

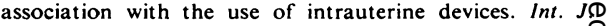
Fertil., 13, 297-300.

Seigel, D. G., and Markush, R. E. (1969). Oral contraceptives anष्ठ relative risk of death from venous and pulmonary thromboembolism in the United States. Amer. J. Epidem., 90, 11-16

Searle, G. D., \& Co. (1962). Proceedings of a Conference, Thrombo:embolic Phenomena in Women. Searle, Chicago.

Shafey, S., and Scheinberg, P. (1966). Neurological syndromes occurring in patients receiving synthetic steroids (ora contraceptives). Neurology (Minneap.), 16, 205-211.

Tausk, M. (1968). Oral contraceptives and the incidence of thrombcsis. In Drug Induced Diseases, pp. 183-209-1 Edited by L. Meyler and H. M. Peck. Excerpta Medicá Foundaticn, Amsterdam.

United States, Food and Drug Administration (1963). Finat Report on Enovid by the Ad Hoc Committee for the EvalN uation of a Possible Etiologic Relation with Thromo boembolic Conditions. Washington, D.C.

United States, Food and Drug Administration (1966). Report on the Oral Contraceptives. Advisory Committee on Obstetrics \& Gynecology. Washington, D.C.

Vessey, M. P., and Doll, R. (1968). Investigation of relation between use of oral contraceptives and thromboembolie disease. Brit. med. J., 2, 199-205.

Vessey, M. P., and Doll, R. (1969). Investigation of relation between use of oral contraceptives and thromboemboliç disease. A further report. Brit. med. J., 2, 651-657.

Vessey, M. P., and Weatherall, J. A. C. (1968). Venous thrombo:embolic disease and the use of oral contraceptives. review of mortality statistics in England and Wales. Lancet 2, 94-96. 